\title{
RECURSOS HUMANOS EM HOSPITAIS ESTADUAIS GERENCIADOS POR ORGANIZAÇÕES SOCIAIS DE SAÚDE: A LÓGICA DO PRIVADO
}

\author{
HUMAN RESOURCES IN STATE HOSPITALS MANAGED BY HEALTH \\ SOCIAL ORGANIZATIONS:THE LOGIC OF THE PRIVATE
}

\author{
RECURSOS HUMANOS EN HOSPITALES ESTATALES ADMINISTRADOS POR \\ ORGANIZACIONES SOCIALES DE SALUD: LA LÓGICA DEL PRIVADO
}

\author{
Lorena Estevam Martins Fernandes ${ }^{1}$ \\ Gabriella Barreto Soares ${ }^{2}$ \\ Fabiana Turino ${ }^{3}$ \\ Elda Coelho de Azevedo Bussinguer ${ }^{4}$ \\ Francis Sodré
}

Resumo Este estudo teve como principal objetivo analisar as políticas de recursos humanos em saúde nos hospitais estaduais gerenciados por organizações sociais de saúde no Espírito Santo. Para tal, efetuouse uma pesquisa qualitativa, elegendo-se como campo de investigação as organizações sociais que gerenciam hospitais públicos no estado. Na coleta de dados, buscaram-se as normativas e os contratos de gestão firmados entre 2008 e 2016 e realizaram-se entrevistas individuais com os gestores de recursos humanos das instituições participantes. Na análise dos materiais de campo, lançou-se mão da técnica de análise de conteúdo, sendo eleitas cinco categorias empíricas de análise dos contratos: modelo de vínculo empregatício, permissão de contratação de pessoa jurídica, percentual de gastos com pessoal, procedimento de contratação de pessoal, metas relativas à gestão de pessoas. As entrevistas foram analisadas pelas unidades de significação como proposto por Kvale. Os resultados demonstraram que os contratos omitem informações exigidas legalmente e possuem aditivos em demasia. As práticas de gestão de pessoas são próprias de empresas privadas, atendendo a algumas orientações do trabalho em saúde, contudo não referenciando o Sistema Único de Saúde. Adotam métodos divergentes das regras do concurso público e da não precarização do trabalho.

Palavras-chave organizações sociais; recursos humanos em saúde; gestão hospitalar.
Abstract The main goal of the present study was to analyze the politics of human resources in health in state hospitals managed by health social organizations in the state of Espírito Santo, Brazil. We conducted a qualitative research, choosing as the field of investigation the social organizations that manage public hospitals in the state. During the data collection process, we sought the regulations and management contracts signed between 2008 and 2016, and performed individual interviews with the human resources managers of the participating institutions. During the analysis of the fieldwork materials, we used the content analysis technique, and chose five empirical categories of analysis of the contracts: the employment relationship model, the permission to hire legal entities, the percentage of expenses with staff, the procedure used to hire staff, and the goals regarding people management. The interviews were analyzed through the units of meaning proposed by Kvale. The results showed that the contracts omit legallyrequired information and have too many amendments. The people management practices are typical of private companies, and follow some guidelines of the work in health, but without reference to the Brazilian Unified Health System (Sistema Único de Saúde, SUS, in the Portuguese acronym). They adopt methods that are different from the rules of the public service entrance exams and the non-precarization of labor.

Keywords social organizations; human resources in health; hospital management. 


\section{Introdução}

O conceito de recursos humanos (RH) evolui e se ressignifica com base na sua definição clássica, proveniente da ciência da administração, subordinada à ótica de quem exerce alguma função de gerência ou de planejamento (capacidade das pessoas, dos recursos materiais e financeiros visando a uma utilização mais racional e eficiente). Também absorve as definições de força de trabalho da economia política e de gestão do trabalho, da sociologia do trabalho. Recursos humanos refere-se a uma mistura que abrange o trabalho, o trabalhador como 'ser social' e a sociedade (Pierantoni, Varella e França, 2006).

As particularidades do trabalho em saúde, como ser coletivo, multidisciplinar, relacional, interativo, tanto entre profissionais como entre profissionais e usuários, consistem em motivos pelos quais os trabalhadores exercem papel estratégico para que o Sistema Único de Saúde (SUS) alcance seus princípios e diretrizes (Santini et al., 2017).

A chamada gestão do trabalho em saúde, que fundamentalmente integra o campo de recursos humanos em saúde (RHS), começou a ter lugar na década de 1990, mais propriamente em sua segunda metade, concomitante - e paradoxalmente - à flexibilização das relações de trabalho. Isso porque os níveis crescentes de flexibilização das relações de trabalho coexistiram com discursos da Reforma Sanitária sobre a emergência de um trabalho revalorizado no SUS, em que prevalecessem a autonomia e a participação (Vieira, 2009).

Diversos problemas se apresentaram para a operacionalização do SUS desde sua implantação. Os principais foram: o financiamento das ações de saúde; a definição clara de funções para os três entes governamentais (federal, estadual e municipal); as formas de articulação público/privado no novo modelo de organização dos serviços; e a resistência do antigo modelo assistencial, baseado na doença e em ações curativas individuais quanto às mudanças efetivas nas práticas assistenciais (Viana e Dal Poz, 2005). Tais dificuldades se refletiram diretamente na estruturação da área de recursos humanos no SUS.

Os hospitais são organizações cujas atividades se mostram bastante complexas, heterogêneas, permeadas por múltiplos interesses, com lugar crítico na prestação de serviços de saúde. Consistem em um espaço de construção de identidades profissionais, com grande reconhecimento social. Na estrutura hospitalar, precisa-se dar atenção especial à gestão de recursos humanos, de modo que os profissionais recebam treinamento permanente para lidar de maneira positiva com as pessoas cuja saúde está fragilizada por doenças e com familiares debilitados pelo sofrimento, como defende Gonçalves (1998).

As políticas de gestão do trabalho são essenciais em qualquer organização onde trabalhem pessoas. A gestão de pessoas envolve o conjunto de políticas e práticas orientadoras de comportamento humano e relações interpessoais 
no trabalho, incluindo gestão estratégica de RH; padrões culturais; captação, formação, movimentação e desenvolvimento de pessoas; relações de trabalho, qualidade de vida no trabalho e gestão de competências (Fleury e Fischer, 1998).

Com as organizações sociais de saúde (OSSs) à frente da gerência dos hospitais públicos em todo o país, com o discurso da eficiência e do envolvimento da sociedade civil (Bresser-Pereira, 2010), a gestão de pessoas torna-se atribuição dessa organização. Visando à globalização, ao gerencialismo e à eficiência presentes nas diversas políticas centradas em processos de reforma, o discurso geralmente se ancora nas propostas de 'diminuição' do Estado, do amortecimento da proteção social do trabalho e dos trabalhadores. Se o foco central da implementação das OSSs, instituições sem fins lucrativos, de um lado estabeleceu na prática metas para a privatização, de outro buscou a flexibilização da gestão, principalmente das relações de trabalho (Pierantoni, 2001; Pierantoni, Varella e França, 2006).

O contrato de gestão, previsto pela lei n. 9.637/98 (Brasil, 1998), é o instrumento de pactuação entre o poder público e as organizações sociais, projetado para garantir a prestação dos serviços públicos de caráter social, de modo a não trazer ao orçamento público grande custo. Pela mencionada lei, as entidades do terceiro setor são incumbidas de desempenhar os serviços sociais, incluindo na área da saúde, em substituição ao Estado, o oferecimento de maior eficiência e qualidade nos serviços prestados à população (Zolet, 2011).

Ao se considerar que os hospitais são os primeiros e principais locais de ação das OSS e que estas representam o próprio governo na execução do SUS, o estudo aqui apresentado propôs-se analisar a política de gestão dos trabalhadores desse sistema que atuam nos hospitais estaduais geridos por OSSs; e investigar se as orientações e os princípios referentes à gestão do trabalho para instituições hospitalares são implementadas pelas OSSs, já que tais normas são importantes instrumentos para a consolidação do SUS e reapresentam a importância do trabalho em saúde.

\section{Características e percurso}

O estudo que deu origem a este artigo teve caráter qualitativo, exploratório e descritivo, filiando-se do ponto de vista epistemológico a uma tradição dos estudos de caráter investigativo, interpretativo e reflexivo. A pesquisa qualitativa é bastante usada para entender o poder e o controle, as construções, as ações, as representações da realidade, a legitimidade dos textos sobre o tema pesquisado; e também por ser apropriada ao estudo de relações sociais. A abordagem qualitativa foi escolhida pois possibilitou investigar, conhecer e discutir como se dá a gestão do trabalho nos hospitais estaduais terceirizados pertencentes ao SUS, na visão de seu gestor e por meio da análise dos contratos de gestão (Sandín Esteban, 2010). 
Quanto aos procedimentos de pesquisa, o critério utilizado para a escolha do campo de investigação foi buscar dados de todos os serviços estaduais geridos por OSSs no estado até então, isto é, das quatro OSSs contratualizadas com os três hospitais estaduais terceirizados no Espírito Santo, pois não apresentavam muita clareza na política de gestão do trabalho adotada. Quando examinados os sítios eletrônicos disponíveis, do governo e das OSSs, não foram encontrados o contrato, o manual de RH e o plano de trabalho, tampouco a política de gestão de pessoas desenvolvida no serviço de saúde. Somada a isso, houve a expansão da implementação do regime de OSSs pelo estado, com o discurso da eficiência na gestão.

Para a coleta dos dados, primeiramente foi realizada uma busca de todos os contratos de gestão dos hospitais no site da Secretaria de Saúde do Espírito Santo (http://saude.es.gov.br/) ou no do portal da transparência (https://transparencia.es.gov.br/), uma vez que são documentos que, pela lei n. 12.527/2011 (Lei de Acesso à Informação - LAI)(Brasil, 2011), devem ser publicizados. No entanto, os contratos não estavam disponíveis nos sites governamentais; então foi necessário que os contratos fossem formalmente solicitados ao Núcleo Especial de Desenvolvimento de Recursos Humanos (NUEDRH) da Secretaria de Estado da Saúde do Espírito Santo (SESA/ES).

As variáveis analisadas nos contratos de gestão apresentaram categorias referentes a questões de recursos humanos/gestão do trabalho, que foram: modelo de vínculo empregatício, permissão (ou não) de contratação de pessoa jurídica, percentual de gastos com pessoal, procedimento de contratação de pessoal pela OSS, metas contratuais relativas à gestão de pessoas. Tais categorias foram criadas mediante as informações relativas a $\mathrm{RH}$ que se almejava obter com base nos contratos, as quais consistem em pontos relevantes e polêmicos no estudo de terceirizações por OSS contidos nas normativas de gestão pública já citadas.

Cabe ressaltar que houve notável limitação para a utilização das informações contidas nos aditivos contratuais, inclusive no que se refere aos recursos humanos, por isso não foram analisadas. Com exceção do objeto e do valor acrescido, os demais conteúdos não estavam padronizados, mas apresentados aleatoriamente, sem regras ou critérios objetivos. Também os dados sobre a gestão de pessoas, além de raros, eram imprecisos nesses documentos.

Posteriormente, foram realizadas as entrevistas com quatro gestores de $\mathrm{RH}$ das OSSs que administram os hospitais estaduais do Espírito Santo. Para isso, foi utilizado um roteiro semiestruturado, elaborado e executado pelos pesquisadores com a finalidade de conhecer a política de gestão de pessoas adotada pela OSS, os processos e procedimentos seguidos, o que a política prevê para os trabalhadores, a relação da gestão com o SUS, que direcionamentos ela segue, a aproximação ou não das ações planejadas e executadas 
com relação às metas do contrato de gestão e a opinião do gestor a respeito da gestão hospitalar por meio de OSS.

Quanto à análise dos dados, em relação aos contratos foi utilizada a análise de conteúdo temática, com o objetivo de "verificar a descoberta do que está por trás dos conteúdos manifestos, indo além das aparências do que está sendo comunicado" (Gomes, 2001, p. 74). Já as entrevistas foram analisadas conforme orientam Kvale (1996) e Duarte (2004). Tratou-se então de ler e reler as transcrições das entrevistas até que nos familiarizássemos com elas, fragmentando o texto transcrito em unidades de significação e reorganizando os fragmentos pelos pressupostos que surgiram. A interpretação das unidades é um procedimento minucioso, de modo a articulá-las entre si, formulando hipóteses explicativas do problema - nesse caso, da política ou das práticas de gestão de pessoas adotadas pela OSS e a relação delas com o tipo de gestão: hospitalar e privada - apesar de se tratar de serviços públicos.

O projeto de pesquisa foi aprovado pelo Comitê de Ética em Pesquisa da Sociedade de Ensino Superior de Vitória, processo n. 52909416.1.0000.5073.

\section{Conteúdos contratuais}

O estado do Espírito Santo teve entre 2008 e 2016 cinco contratos assinados e 27 aditivos. O número de aditivos é aproximadamente cinco vezes maior que o de contratos celebrados. O aditivo pode ser usado em qualquer momento da execução do contrato em que se perceba necessidade de alteração de cláusula contratual. Suas principais utilidades são a modificação do projeto ou das especificações, o acréscimo ou diminuição quantitativa do objeto, o aumento ou redução de quantitativos, a modificação do regime (e prazo) de execução ou da forma de pagamento.

Em todos os contratos pesquisados, estava registrada a previsão de vigência de sessenta meses. Seus aditivos começaram ainda no primeiro ano de execução. No decorrer do segundo ano, em comparação ao repasse financeiro inicial, três contratos em hospitais ampliaram os repasses em 94\%, 100\% e $159 \%$, respectivamente. A partir do terceiro ano contratual, os acréscimos por aditivo foram de: $148 \%$ no primeiro contrato; $60 \%$ a cada seis meses no segundo contrato; e $26 \%$ de acréscimos no terceiro contrato. Dois desses contratos tiveram cerca de dez aditivos em quatro anos, e um deles teve quatro aditivos em três anos. Sobre as alterações quantitativas no contrato, verificamos que:

O interesse público é não só o fundamento da mutabilidade nos contratos administrativos, como também irá definir o seu real limite. É exatamente em nome dessa mutabilidade dos contratos administrativos que a administração, buscando sempre a realização do interesse público, poderá promover alterações contratuais unilaterais, dentro dos limites indicados (Furtado, 2000, p. 41). 
Esses limites estão no art. $65, \S 1^{\circ}$, da lei n. 8.666/93, que dispõe:

O contratado fica obrigado a aceitar, nas mesmas condições contratuais, os acréscimos ou supressões que se fizerem nas obras, serviços ou compras, até $25 \%$ (vinte e cinco por cento) do valor inicial atualizado do contrato, e, no caso particular de reforma de edifício ou de equipamento, até o limite de 50\% (cinquenta por cento) para os seus acréscimos (Brasil, 1993).

A determinação administrativa não poderá exceder esses limites. Contudo, essa regra não foi devidamente acolhida pelos gestores estaduais, com diversos casos de valores aumentados muita acima do tolerado pela lei. Percebe-se que um número elevado de aditivos com grande acréscimo de gastos frequentemente demonstra falta de planejamento orçamentário financeiro e preços majorados.

Já sobre as alterações qualitativas ao contrato, evidencia-se a necessidade de alterações contratuais, a imutabilidade da essência do objeto contratado, a exequibilidade da nova avença para o contratado. A administração pública deve demonstrar que alteração qualitativa do contrato compõe a alternativa mais adequada ao alcance do interesse público, comparada à possibilidade de rescisão contratual, de realização de nova licitação e de posterior contratação, levando-se em consideração princípios norteadores da atividade administrativa (Couto, 2009).

Não foram observados nos conteúdos contratuais justificativas expressas nem critérios precisos para esse aumento em demasia, ficando comprometida a observação aos princípios da razoabilidade e da publicidade.

Das categorias de análise elaboradas relativas ao conteúdo dos contratos de gestão, cinco delas contêm informações afins à política de recursos humanos adotada pela gestão. No Quadro 1 temos descritas essas informações, os resultados de sua análise. A explicação de cada categoria está na terceira coluna do Quadro 1. 


\section{Quadro 1}

Categorias analisadas nos contratos de gestão firmados entre as organizações sociais de saúde e o estado do Espírito Santo (2008-2016)

\begin{tabular}{|c|c|c|}
\hline $\begin{array}{l}\text { Informações } \\
\text { contratuais }\end{array}$ & Resultado & Significado/Objetivo \\
\hline $\begin{array}{l}\text { Modelo de vínculo } \\
\text { empregatício }\end{array}$ & CLT + cedidos & $\begin{array}{l}\text { Incidiu na contratação de pessoal realizada pela OSS mediante o } \\
\text { regime celetista acrescida da recepção de servidores do Estado, } \\
\text { provenientes de outros organismos estatais, cedidos para } \\
\text { desempenharem suas atividades na OSS. As outras possibilidades } \\
\text { seriam: exclusivamente CLT, exclusivamente cedidos. }\end{array}$ \\
\hline $\begin{array}{l}\text { Permissão de contratação } \\
\text { de pessoa jurídica }\end{array}$ & Sim & $\begin{array}{l}\text { Indicação de permissão ou de vedação de contratação de pessoa } \\
\text { jurídica para a prestação de serviços na OSS. Convencionaram-se três } \\
\text { respostas possíveis para essa categoria: sim; não; omisso. }\end{array}$ \\
\hline $\begin{array}{l}\text { Percentual de gastos com } \\
\text { pessoal }\end{array}$ & $70 \%$ do valor global & $\begin{array}{l}\text { Identificação no contrato de gestão do percentual estabelecido para } \\
\text { os gastos com recursos humanos, ou seja, com a contratação das } \\
\text { pessoas que trabalham no hospital. }\end{array}$ \\
\hline $\begin{array}{l}\text { Procedimento de } \\
\text { contratação de pessoal } \\
\text { pela OSS }\end{array}$ & Omisso & $\begin{array}{l}\text { Identificar como foi feito para contratar os trabalhadores e se } \\
\text { no contrato de gestão há alguma indicação da possibilidade de } \\
\text { contratação de serviços via empresas terceirizadas, cooperativas ou } \\
\text { outras modalidades. }\end{array}$ \\
\hline Metas de RH & $\begin{array}{l}\text { O contrato de } 2008 \\
\text { possui' }{ }^{1} \text {, porém não } \\
\text { está vigente. }\end{array}$ & $\begin{array}{l}\text { Categorias que expressaram a relação dos objetivos a serem } \\
\text { atingidos pela OSS no desempenho de suas atividades, as quais } \\
\text { são expressas em termos quantitativos ou percentuais, com } \\
\text { estabelecimento de um prazo determinado para cumprimento, e } \\
\text { que implicam o recebimento de recursos para tal alcance - lei n. } \\
9.637 / 98 \text {, art. } 70 \text {, inc. I (Brasil, 1998). Na pesquisa aqui apresentada, } \\
\text { foram consideradas apenas as metas ligadas a questões de recursos } \\
\text { humanos. }\end{array}$ \\
\hline
\end{tabular}

Fonte: Elaboração própria.

Nota: CLT - Consolidação das Leis Trabalhistas ; OSS: organizações sociais de saúde; RH: recursos humanos.

Nota 1: São elas: "Metas Qualitativas: Ensino e pesquisa (Plano Diretor Educacional; Programação semestral de eventos técnicos científicos; evento técnico científico por semestre; regimento de estagiários; programa de educação permanente em suporte avançado de vida para médico e enfermeiros); Qualidade (Avaliação de satisfação do usuário; Avaliação de satisfação dos colaboradores); Gestão de implantação do programa de capacitação e desenvolvimento de colaboradores".

No Espírito Santo, conforme indicado no Quadro 2, há três hospitais geridos por OSSs. O primeiro deles foi o Hospital Estadual Central, por meio de contrato entre a Secretaria de Estado da Saúde e a Pró-Saúde (Associação Beneficente de Assistência Social e Hospitalar), publicado em 11 de setembro de 2008.

\section{Quadro 2}

Hospitais, OSSs e contratos de gestão no Espírito Santo

\begin{tabular}{|llll|}
\hline Hospital & Sigla da OSS & N. do contrato de gestão (CG) & Início do CG \\
\hline HEC & Pró-Saúde & 1 CG +4 AD & 2008 \\
(encerrado) & ACSC & $1 \mathrm{C}+11$ AD & 2011 \\
HEC & lapemesp & $1 \mathrm{C}+2 \mathrm{AD}$ & 2014 \\
HEUE & Pró-Saúde & $1 \mathrm{C}$ & 2015 \\
(encerrado) & $1 \mathrm{C}+10 \mathrm{AD}$ & 2012 \\
HEUE & Aebes & & \\
\hline
\end{tabular}

Fonte: Elaboração própria.

Nota: HEC - Hospital Estadual Central; HEUE - Hospital Estadual de Urgência e Emergência; HJSN - Hospital Estadual Dr. Jayme dos Santos Neves; ACSC - Associação Congregação de Santa Catarina; lapemesp - Instituto Americano de Pesquisa, Medicina e Saúde Pública; Pró-Saúde - Associação Beneficente de Assistência Social e Hospitalar; Aebes - Associação Evangélica Beneficente Espírito-Santense ; C - Contrato; CG - Contrato de gestão; AD - Aditivos. 
No contrato da OSS Pró-Saúde para gestão do HEC iniciado em 2008, encontra-se um termo de desligamento apontando que ocorreu por 'rescisão contratual amigável', o que não foi observado em nenhum outro contrato. Cabe ressaltar que são necessárias a comprovação de conveniência para a administração e a configuração dos motivos para a rescisão unilateral do acordo, caso contrário constitui irregularidade por ofensa ao art. 79, inciso II, da lei n. 8.666/1993 (Tribunal de Contas da União, 2013). Todavia, tanto a portaria n. 418-S, de 25/11/2011, publicada no Diário Oficial do Espírito Santo (DIOES) em 28/11/2011 (Diário Oficial do Estado do Espírito Santo, 2011), a qual trata da rescisão desse contrato, assim como o próprio termo de rescisão do contrato não trazem registros da motivação da rescisão amigável, conforme orientado na legislação. Em 2015, a Pró-Saúde voltou a ser contratada para gestão de outro hospital estadual.

A rede de hospitais gerenciados por OSSs no Espírito Santo sofre influência de outros estados brasileiros. Das quatro OSSs que já contratualizaram com o estado, uma surgiu e cresceu com as parcerias públicas no Espírito Santo, a Associação Evangélica Beneficente Espírito-Santense (Aebes). Esta instituição possui titulação de filantropia e atua em três municípios da região metropolitana capixaba, gerenciando uma maternidade municipal e administrando um hospital filantrópico próprio.

Sobre o modelo de vínculo, os contratos trazem a previsão de cessão nos seguintes termos: é atribuição da contratada "responsabilizar-se pela contratação de pessoal necessário para execução das atividades previstas (...) através de contratação direta ou de terceiros, pessoas físicas e/ou jurídicas"; e a parte que cabe à contratante, a obrigação de "promover (...) o afastamento de servidores públicos para terem exercício na organização social".

O contrato de 2014 com o Iapemesp traz um texto inusitado e inédito até então:

A SESA fornecerá corpo clínico especializado, nas seguintes especialidades médicas: Ortopedia; cirurgia vascular; Cirurgia geral; cirurgia plástica; Anestesiologia; Neurocirurgia; Intensivistas. A Organização Social deverá contratar serviços, RH e corpo clínico especializados que se fizerem necessários à gestão do Hospital Estadual São Lucas.

Assim, entende-se que o Hospital São Lucas, objeto desse contrato com a Iapemesp, é o mesmo Hospital Estadual de Urgência e Emergência (HEUE), mas com outra personalidade jurídica, ao passo que ela foi contratada para gestão do serviço de pronto-socorro do hospital. O contrato de gestão que o sucede em 2015, após a intervenção da SESA, agora com a OS Pró-Saúde, utiliza no instrumento vigente o nome Hospital Estadual de Urgência e Emergência. 
Os contratos omitem informações sobre o processo de recrutamento e seleção, não explicitando compromissos acerca de algo tão importante na boa execução de um serviço de saúde. A instituição precisa apresentar um quadro com atribuições de cada cargo, descritas as funções, os requisitos, o perfil, a quantidade de pessoas e o tempo estimado para cada serviço. Esse dimensionamento é base para o preenchimento das vagas, a efetuação das substituições, os remanejamentos, o cálculo da diminuição ou a ampliação do número de funcionários (Bittar, 1996; Laverde, 2000). Essa fase também contempla especificar se o recrutamento será por fontes internas, externas ou ambas, assim como a divulgação e as inscrições - e se a seleção será direta, com entrevista, provas, quais os critérios de escolha e de contratação.

Um agravante no presente instrumento é a cessão de servidores públicos (art. 14 da lei n. 9.637, de 1998 [Brasil, 1998]), prevista nos contratos de gestão do ES. O que se observa é o próprio poder público arcando diretamente com o pagamento da remuneração do trabalhador, ao mesmo tempo possibilitando à prestadora de serviços contratar e subcontratar - sem limites trabalhadores e prestadores de serviços para as unidades públicas de saúde. Ou seja, há duplamente o gasto de recursos financeiros para a mesma questão (Margarida, 2011).

Na cessão de funcionários públicos para prestar serviços juntamente com as OSSs, custeados pelo próprio ente estatal, percebe-se que além de o Estado custear o quadro de pessoal das entidades, fica dispensada a prévia aprovação em concurso público para a ocupação das vagas destinadas aos servidores públicos. Assim, os servidores aprovados em concurso para a ocupação de determinado cargo são desregradamente removidos para o trabalho com as entidades privadas. Tal possibilidade está em desacordo com o contexto de normas que orientam a administração pública, e diante disso se tornou objeto de rígidas críticas por parte da doutrina jurídica (Zolet, 2011).

Outro ponto é que as OSSs não possuem personalidade jurídica de direito público, mas de direito privado. As pessoas que prestaram concurso público não devem exercer suas atividades nelas, sob pena de total desvio de função.

O primeiro contrato estadual (ano de 2008, Hospital Estadual Central) tem um diferencial: é o único que descreve nas condições de pagamento (cláusula oitava) que a OSS receberá recursos financeiros para fazer recrutamento, seleção, contratação e treinamento de pessoas; é o único que traz o alcance de metas ligadas a RH, as quais estão descritas no Quadro 1 .

Todos os contratos permitem expressamente a contratação de pessoa jurídica pelas OSSs, apontando a presença do fenômeno 'pejotização' ${ }^{6}$ no âmbito da saúde. Contudo, concordamos que não é possível uma pessoa jurídica ser considerada um trabalhador; assim, sua contratação é uma prática irregular e ilícita - porque a pejotização viola os princípios trabalhistas de onerosidade, 
não eventualidade, pessoalidade e necessidade de prestação laborativa com reciprocidade por meio de promessas fantasiosas de ganhos comissionados, regras produtivas falsas e a constante subordinação (Margarida, 2011).

Na contratação de pessoas jurídicas não há horário de trabalho preciso, nem o elemento empregatício, nem garantia dos direitos trabalhistas provenientes do vínculo de trabalho. Logo, tal prática infringe as relações trabalhistas (descumpre os art. $2^{\circ}$ e $3^{\circ}$ da CLT), precariza a função do trabalhador e é contra o empregado (Margarida, 2011).

Uma das principais funções de uma organização social na gestão é a contratação de pessoas para realizar serviços públicos; assim, é possível se entender o valor da quantia de gastos com pessoal (70\% do valor de custeio) prevista no contrato. Só se justifica ter uma OSS na gestão se for para ela contratar pessoas em nome do Estado, em quantidades superiores às permitidas a ele.

Acredita-se que a criação da Lei de Responsabilidade Fiscal (lei complementar n. 101, de 2000)(Brasil, 2000), que estabelece o limite de 60\% para contratações de mão de obra pelos poderes públicos estaduais - tão logo depois da lei federal n. 9.637 (Brasil, 1998) e da lei estadual n. 846, ambas de 1998 -, veio colaborar para o crescimento das terceirizações e das parcerias público-privadas (e até incentivar esse crescimento), com a justificativa de possibilitar o aumento das contratações de pessoas e a ampliação do quadro de RH (Rodrigues, 2016). Não é possível fazer política pública de saúde sem pessoas - médicos, enfermeiros, dentistas, psicólogos -, pondera esse autor. Ao invés de fazer as políticas sociais com servidores públicos, o Estado propôs-se a repassar os recursos públicos para que o setor privado contratasse os profissionais. O limite talvez não tenha reduzido o gasto com pessoal; apenas transferiu esse gasto para o setor privado, que os contrata com os recursos públicos.

Os elementos contidos nos contratos de gestão referentes à política de RH são pouco específicos. Nos contratos e aditivos estão omissos a política de $\mathrm{RH}$, os procedimentos para recrutamento, seleção, desenvolvimento e acompanhamento dos trabalhadores, assim como metas relativas à gestão de pessoas.

O contrato de gestão se constitui em um instituto do direito administrativo-constitucional, que deve ter o imperativo de proporcionar a transparência e a racionalidade estatal. Esse contrato pode ser enaltecido por propiciar à administração pública, na prestação dos serviços públicos, fazer uso da eficiência das empresas; mas também é fortemente criticado por permitir a ela que aumente sua liberdade de ação, com a flexibilização do regime jurídico administrativo, pondo em xeque alguns princípios constitucionais (Schimitt, 2006). 


\section{Práticas de gestão de pessoas}

Todos os gestores referiram-se à OSS usando as palavras 'empresa' e 'instituição privada'. Um mencionou sete vezes e outro, dez. Podemos concluir que, embora autores (Bresser-Pereira, 2000; Bresser-Pereira e Grau, 1999) expressem a ausência de caráter privatizante das organizações sociais, os gestores de RH das OSSs gestoras de hospitais no Espírito Santo consideram as OSSs como empresas ou instituições privadas.

Todos os entrevistados disseram ter processo seletivo para contratar empregados, pois afirmaram não possuir servidor público cedido, apesar de o contrato permitir. Eles relataram ter os cargos e funções descritos, assim como os respectivos salários, afirmando inclusive ser exigência do contrato de gestão.

Bittar (1996) ressalta que a subárea mais importante que compõe a estrutura organizacional hospitalar, ou de qualquer outra instituição, principalmente do setor de serviços, é a de RH. A gestão desta parte depende da quantificação e da qualificação dos trabalhadores do hospital, da provisão do cuidado com o usuário em condições de urgência e emergência, dos cuidados especializados e intensivos, de possuir margem de erro zero e os melhores profissionais.

Segundo Bittar (1996), os serviços tradicionalmente terceirizados por hospitais eram os de manutenção e limpeza, mas atualmente há uma grande quantidade de profissionais de saúde subcontratados ou 'quarteirizados'. Os quantitativos de profissionais que atuam nos hospitais e o total de profissionais terceirizados declarados por seus gestores estão descritos no Quadro 3.

Quadro 3

Quantidade de profissionais por hospital

\begin{tabular}{|lllll|}
\hline Caracterização & OSS A & OSS B & OSS C & OSS D \\
\hline Quantidade de contratados diretamente & 620 & 620 & 580 & 1.620 \\
Quantidade de terceirizados & Não especificado & 200 & 214 & 800 \\
\hline
\end{tabular}

Fonte: Elaboração própria.

O percentual de terceirizados nos hospitais capixabas geridos por OSSs é de $24 \%, 27 \%$ e $33 \%$ (nas entidades B, C e D, respectivamente) de seu número total de empregados. Os tipos são variados, tais como: serviços de diagnóstico por imagem, laboratório, alimentação, lavanderia, avaliação psicológica, vigilância e acesso, higienização e limpeza, segurança patrimonial, banco de sangue, nutrição e fisioterapia. Para os serviços de medicina, fonoaudiologia e alguns tipos de fisioterapias, os profissionais são contratados como pessoa jurídica.

Terceirizar tantos serviços não nos parece uma prática de RH coerente e acertada, já que "a terceirização, que se acentua na realidade como um modo de trabalho e de vida, apresenta-se para o trabalhador como uma forma de 
flexibilização e precarização das seções de trabalho, sempre associada a perda de direitos" (Carvalho, 2010, p. 59-60).

Ao se considerar que as terceirizações por si só já constituem uma modalidade de trabalho precarizado (Antunes, 2008), somando-se o fato de que as organizações sociais são uma forma de terceirização (Bresser-Pereira, 1999), constatamos que adotar o modelo gerencial por OS é uma forma de precarizar o trabalho humano, já que os direitos outorgados para os profissionais da saúde pública não são viabilizados pela OSS. Tal situação transparece nas modalidades de contratação, na falta de autonomia, na ausência de planos de carreira, nas ferramentas de gestão - foco prioritário na produtividade, vínculos trabalhistas frágeis, jornadas exaustivas, intransigente satisfação do cliente -, que desconsideram o empregado como sendo o trabalhador de uma política pública, cujos diretos trabalhistas deveriam estar consolidados e implementados, mas não estão.

Os entrevistados disseram que suas OSSs não contratam médicos diretamente, mas por meio de pessoa jurídica. Essa prática, apesar de se mostrar como legítima e corriqueira, pode ser considerada um ato de fraude para o sistema jurídico (Carpes, 2011; Barros, 2015; Toni, 2015). A pejotização na relação laboral pode significar a flexibilização, pois permite postura distante entre empregado e empregador, em um acordo de trabalho que pode prejudicar o empregado e significar relação de trabalho material (Misailidis e Pessanha, 2016).

Os gestores afirmaram ainda que relacionam indicadores de $\mathrm{RH}$, apesar da não exigência contratual; possuem educação permanente, mesmo que restrita à área técnica e operacional, e ações de valorização do trabalhador, na maior parte das vezes utilizando a própria equipe e serviços voluntários da comunidade. Todos citaram a rotatividade como um problema, o qual incide principalmente na equipe de enfermagem, principalmente nos técnicos. Os principais motivos constatados são a exaustão causada pelos vários vínculos de trabalho, a instabilidade no emprego e os baixos salários.

As OSSs não fazem avaliação de desempenho nem adotam plano de carreiras. Duas delas planejam fazer isso nos próximos anos, visando à retenção da mão de obra. Apenas uma não possui plano de cargos e salários definido.

Dos Santos e Lacaz (2013, p. 4), ao considerarem que os efeitos da reforma do Estado e a flexibilização do trabalho em saúde geram sua precarização, acreditam que "a adoção dos Planos de Carreiras, Cargos e Salários (PCCS) e sua implantação na gestão dos serviços de saúde pode ser uma saída para diminuir os efeitos da precarização das relações de trabalho". Os autores afirmam que o PCCS se constitui num instrumento que assegura a profissionalização e a valorização de todos os trabalhadores da saúde, enfatizando as especificidades 
do setor e promovendo a constituição de um quadro de pessoal habilitado para lidar com tais especificidades.

A qualidade é, como a eficiência, um dos principais discursos a favor da gestão por OS, porém apenas uma entidade possui métodos gerenciais para medi-la. Não há metas de RH contratualizadas, afirmaram todos os gestores, nem previsão de recursos financeiros para política de RH. Todos citaram a gestão pública como burocrática e deficiente, e afirmaram a organização social como tendência, solução para a gestão hospitalar, pois 'ajudam' o Estado a ser eficiente.

Nenhum entrevistado citou o SUS como princípio para as práticas de $\mathrm{RH}$, demonstrando escasso conhecimento da política de gestão do trabalho do SUS, assim como do conteúdo do contrato de gestão.

As organizações sociais podem assumir face pública e face privada, de acordo com sua conveniência - estatal para receber recursos públicos, privada para gerir esses recursos com autonomia e definir as normas de funcionamento do serviço a ser gerido. Assim, pode-se argumentar que as organizações sociais tenham sido uma 'manobra' adotada por setores políticos neoliberais para que o Estado atuasse apenas administrativamente em alguns serviços, sob fiscalização 'flexibilizada' nos procedimentos públicos do seu regime jurídico (Almeida, 2004).

\section{Considerações finais}

Os dados apresentados e discutidos neste artigo nos levaram a concluir que, primeiramente, nos contratos de gestão estaduais pesquisados, há permissões distantes dos princípios da administração pública e das normas jurídico-administrativas. Observa-se que os aditivos contratuais dilatam vigência e acrescem objeto, ampliando severa e deliberadamente os repasses financeiros. Permanece o questionamento: o elevado número de aditivos ocorreu devido à falta de planejamento dos gastos públicos ou à decisão consciente do gestor público de ampliar em demasia os repasses financeiros à iniciativa privada?

Os entes privados na parceria com o poder público também necessitam de melhor definição de sua função e de suas áreas de atuação. Os instrumentos precisam ter metas claras, prazos, preços, penalidades, rescisão (Santos, 2010). Acima de tudo, há que cumprir o que estiver acordado. A terceirização é uma realidade na gestão pública, criada para atuar de forma 'complementar' e não 'substitutiva' ao Estado.

Os resultados encontrados confirmaram que as OSSs se afastam das regras do concurso público e da não precarização do trabalho. Fazem 'quarteirização' e 'pejotização' indiscriminadamente, por permissão contratual. Seus empre- 
gados são profissionais de saúde responsáveis pela execução dos serviços de assistência e cuidado em hospitais públicos do SUS, contudo não são considerados trabalhadores do SUS. Eles não são respaldados pelos mesmos direitos deles; talvez o sejam pelos deveres. Além disso, as OSSs relataram práticas e políticas próprias de gestão de pessoas, semelhante às de empresas privadas; demonstraram atender a vários critérios estabelecidos nas normas e orientações da gestão do trabalho em saúde; declararam ter setor estruturado de saúde e segurança do trabalhador e ações junto aos trabalhadores visando à superação de práticas inadequadas e ao aprimoramento do acolhimento, do cuidado e de humanização.

Entretanto, disseram que não recebem recursos financeiros específicos para gestão de RH, o que se expressa na ausência de metas e, consequentemente, no não monitoramento obrigatório pelo órgão gestor público. O motivo relatado pelo qual ainda assim possuem indicadores e metas de RH é manter a eficiência e a qualidade dos serviços prestados.

Contraditório é não possuírem meios adequados para medir tal qualidade. Apenas uma instituição dispõe de setor e sistema de monitoramento da qualidade estruturado. Os gestores consideraram atuar em instituições privadas e disseram tratar os usuários como clientes, os quais deveriam ser vistos como cidadãos de direitos - nesse caso, principalmente do direito universal à saúde. Declararam ter ciência de que foram contratados principalmente para contratar pessoas, pois o governo tem regras e limites legais para contratar seus próprios trabalhadores.

O trabalho aqui apresentado também nos levou a questionar se a adoção do regime de OSS para gestão dos serviços de saúde pública pode não ser a solução para questões relativas aos trabalhadores da saúde nos estados. Os novos arranjos institucionais na relação público versus privado no setor saúde, especialmente das OSSs, afasta, progressivamente, os mecanismos de isonomia entre os profissionais, ao passo que apresenta para o SUS o desafio de rever as maneiras de tratar as relações de trabalho, a diversidade de formas de seleção, contratação, vínculo e remuneração (Barbosa, 2010). 


\section{Colaboradores}

Lorena Estevam Martins Fernandes atuou na concepção e no delineamento das ideias; na coleta, análise e interpretação dos dados; na redação e revisão do artigo. Gabriella Barreto Soares participou da coleta, análise e interpretação dos dados; na redação e revisão de conteúdo do artigo. Fabiana Turino contribuiu na coleta, análise e interpretação dos dados; e na revisão de conteúdo do artigo. Elda Coelho de Azevedo Bussinguer atuou na coordenação da pesquisa e apresentou sugestões importantes incorporadas ao trabalho. Francis Sodré foi responsável pela coordenação geral da pesquisa; na orientação da redação e na revisão de conteúdo do artigo.

Resumen Este estudio tuvo como principal objetivo analizar las políticas de recursos humanos en salud en los hospitales estatales administrados por organizaciones sociales de salud en el Estado de Espírito Santo. Para esto, se efectuó una investigación cualitativa, seleccionando como campo de investigación las organizaciones sociales que administran hospitales públicos en el estado. En la recolección de datos, se buscaron las normativas y los contratos de gestión firmados entre el 2008 y el 2016, y se realizaron entrevistas individuales con los gestores de recursos humanos de las instituciones participantes. En el análisis de los materiales de campo, se empleó la técnica de análisis de contenido, siendo elegidas cinco categorías empíricas de análisis de los contratos: modelo de vínculo laboral, permiso de contratación de persona jurídica, porcentaje de gastos de personal, procedimiento de contratación de personal, metas relativas a la gestión de las personas. Las entrevistas se analizaron a partir de las unidades de significado como propone Kvale. Los resultados demostraron que los contratos omiten información requerida por ley y presentan un alto número de condiciones adicionales. Las prácticas de gestión de personas son propias de empresas privadas, cumpliendo algunas de las orientaciones de trabajo de la salud, pero sin hacer referencia al Sistema Único de Salud. Adoptan métodos divergentes de las reglas de licitación o concurso público y de la no precarización del trabajo.

Palavras clave organizaciones sociales; recursos humanos en salud; gestión hospitalaria.

\section{Notas}

${ }^{1}$ Universidade Federal do Espírito Santo, Programa de Pós-Graduação em Saúde Coletiva, Vitória, Espírito Santo, Brasil.

$<$ lorenaestevam@hotmail.com>

Correspondência: Universidade Federal do Espírito Santo, Programa de Pós-Graduação em Saúde Coletiva (Prédio da Enfermagem), Av. Marechal Campos, 1.468, CEP 29043900, Maruípe, Vitória, Espírito Santo, Brasil.

${ }^{2}$ Universidade Federal do Espírito Santo, Programa de Pós-Graduação em Saúde Coletiva, Vitória, Espírito Santo, Brasil.

<gabriella.barreto@yahoo.com.br> 


\footnotetext{
${ }^{3}$ Universidade Federal do Espírito Santo, Programa de Pós-Graduação em Saúde Coletiva, Vitória, Espírito Santo, Brasil.

<turino.fabiana@gmail.com>

${ }^{4}$ Faculdades Integradas de Vitória, Programa de Pós-Graduação em Direitos e Garantias Fundamentais, Vitória, Espírito Santo, Brasil.

<elda.cab@gmail.com>

${ }^{5}$ Universidade Federal do Espírito Santo, Programa de Pós-Graduação em Saúde Coletiva, Vitória, Espírito Santo, Brasil.

<francisodre@uol.com.br>

${ }^{6}$ A denominação 'pejotização' refere-se à contratação de serviços pessoais, exercidos por pessoas físicas, de modo subordinado, não eventual e oneroso, realizada por meio de pessoa jurídica constituída especialmente para esse fim, na tentativa de dissimular relações de emprego existentes, fomentando a ilegalidade e burlando direitos trabalhistas (Brianezi, 2011).
}

\section{Referências}

ALMEIDA, Karen S. Organizações sociais: (des)controle social e restrições ao direto à saúde. Revista SER Social, Brasília, n. 15, p. 115-140, jul.-dez. 2004.

ANTUNES, Ricardo. Século XXI: nova era da precarização estrutural do trabalho? SEMINÁRIO NACIONAL DE SAÚDE MENTAL E TRABALHO, 2008. São Paulo: Fundacentro, 2008. Disponível em: $<$ http://www.fundacentro.gov.br/Arquivos/sis/EventoPortal/ AnexoPalestraEvento/Mesa \%201\%20-\%20 Ricardo\%20Antunes\%20texto.pdf $>$. Acesso em: 10 jan. 2016.

BARBOSA, Nelson B. Regulação do trabalho no contexto das novas relações público versus privado na saúde. Ciência \& Saúde Coletiva, Rio de Janeiro, v. 15, n. 5, p. 2.497-2.506, 2010.

BARROS, Aline M. A pejotização como fraude na relação trabalhista. 2015. Disponível em: <https:/juridicocerto.com/p/luizmarcelobarros/ artigos/a-pejotizacao-como-fraude-na-relacaotrabalhista-1202>. Acesso em: 15 out. 2016.
BITTAR, Olímpio J. N. V. Hospital: qualidade e produtividade. São Paulo: Sarvier, 1996.

BRASIL. Lei ordinária n. 8.666, de 21 de junho de 1993 (Lei de Licitações). Diário Oficial da União, Poder Executivo, Brasília, DF, 22 junho 1993. Seção 1, pág. 8.269.

BRASIL. Lei n. 9.637, de 15 de maio de 1998. Dispõe sobre a qualificação de entidades como organizações sociais, a criação do Programa Nacional de Publicização, a extinção dos órgãos e entidades que menciona e a absorção de suas atividades por organizações sociais, e dá outras providências. Diário Oficial [da] República Federativa do Brasil, Poder Executivo, Brasília, DF, 18 maio 1998, Seção 1, pág. 8.

BRASIL. Lei n. 12.527, de 18 de novembro de 2011. Regula o acesso a informações previsto no inciso XXXIII do art. $5^{\circ}$, no inciso II do $\S 3^{\circ}$ do art. 37 e no $\S 2^{\circ}$ do art. 216 da Constituição Federal; altera a lei n. 8.112, de 11 de dezembro de 1990; revoga a lei n. 11.111, de 5 de maio de 2005, e dispositivos da lei n. 8.159, de 8 de janeiro de 1991; e dá outras providências. 
Diário Oficial [da] República Federativa do Brasil, Brasília, DF, 18 novembro 2011, pág. 1, edição extra. Disponível em <http://www. planalto.gov.br/ccivil_03/_ato2011-2014/2011/ lei/112527.htm>. Acesso em: 23 out. 2015.

BRASIL. Lei n. 101, de 4 de maio de 2000. Estabelece normas de finanças públicas voltadas para a responsabilidade na gestão fiscal e dá outras providências. Disponível em: <http:// www.planalto.gov.br/ccivil_03/leis/lcp/lcp101. htm>. Acesso em: 15 out. 2015.

BRESSER-PEREIRA, Luís C. A reforma gerencial do Estado de 1995. Revista de Administração Pública, Rio de Janeiro, n. 34 v. 4, p. 7-26, jul.-ago. 2000.

BRESSER-PEREIRA, Luís C. Democracia, Estado Social e reforma gerencial. Revista de Administração de Empresas, São Paulo, v. 50, n. 1, p. 112-116, jan.-mar. 2010.

BRESSER-PEREIRA, Luís C. Reflexões sobre a reforma gerencial brasileira de 1995. Revista do Serviço Público, Brasília, ano 50. n. 4. p. 5-29, out-dez. 1999.

BRESSER-PEREIRA, Luís C.; GRAU, Nuria C. (orgs.). O público não estatal na reforma do Estado. Rio de Janeiro: Editora FGV, 1999.

BRIANEZI, Katy. "Pejotização", você sabe o que significa?. 2011. Disponível em: < https:// katybrianezi.jusbrasil.com.br/artigos/121934275/ pejotizacao-voce-sabe-o-que-significa $>$ Acesso em: 22 nov. 2016.

CARPES, Camilla L. A contratação de pessoas físicas como pessoas jurídicas em fraude ao direito do trabalho: o fenômeno da pejotização, 2011. Disponível em: <http://www3.pucrs. br/pucrs/files/uni/poa/direito/graduacao/tcc/ tcc2/trabalhos2011_2/camilla_carpes.pdf > . Acesso em: 19 mar. 2016.

CARVALHO, Maria A. Pejotização e descaracterização do contrato de emprego: o caso dos médicos em Salvador, Bahia. 153f. Dissertação (Mestrado em Políticas Sociais e Cidadania)
- Universidade Católica do Salvador, Salvador, 2010 .

COUTO, Daniel U. C. A controvérsia sobre os limites das alterações qualitativas dos contratos administrativos. Revista do Tribunal de Contas do Estado de Minas Gerais, Belo Horizonte, v. 70, n. 1, ano XXVII, p. 78-92, jan.-mar. 2009.

DIÁRIO OFICIAL DO ESTADO DO ESPÍRITO SANTO (DIO-ES). Portaria n. 418-S, de 25/11/2011, da Secretaria de Estado da Saúde, 28 nov. 2011, Seção Executivo, pág. 19.

DUARTE, Rosália. Entrevistas em pesquisas qualitativas. Educar em Revista, Curitiba, v. 20, n. 24, p. 213-225, 2004.

FLEURY, Maria T. L.; FISCHER, Rosa M. Gestão de pessoas: os desafios de aproximar a teoria da prática e vice-versa. Revista de Administração RAUSP, São Paulo, v. 33, n. 2, p. 90-94, abr.-jun. 1998.

FURTADO, Lucas R. Contratos administrativos e contratos de direito privado celebrados pela administração pública. Revista TCU, Brasília, v. 31. n. 86. p. 41-59, out-dez. 2000.

GOMES, Romeu. A análise de dados em pesquisa qualitativa. In: MINAYO, Maria C. S. (org.) Pesquisa social: teoria, método e criatividade. 18. ed. Petrópolis: Vozes, 2001. p. 67-79.

GONÇALVES, Ernesto L. Estrutura organizacional do hospital moderno. Revista de Administração de Empresas, São Paulo, v. 38, n. 1, p. 80-90, jan.-mar. 1998.

KVALE, Steinar. Interviews: an introduction to qualitative research interviewing. Thousand Oaks: Sage, 1996.

LAVERDE, Gabriel P. Recursos humanos. In: MALAGÓN-LONDOÑO, Gustavo; MORERA, Ricardo G.; LAVERDE, Gabriel P. Administração hospitalar. 2. ed. Tradução de Antonio Francisco Dieb Paulo. Rio de Janeiro: Guanabara Koogan, 2000. p. 96-116. 
MARGARIDA, Silvânia M. A. O direito do trabalho e o fenômeno da pejotização em sua origem, contextualização e consequências. Âmbito Jurídico, Rio Grande, v. 14, n. 84, jan. 2011. Disponível em: <http://www.ambito-juridico. com.br/site/index.php?n_link=revista_artigos_leitura\&artigo_id=8824>. Acesso em: 13 dez. 2016.

MISAILIDIS, Mirta G. L. M.; PESSANHA, Vanessa V. Direito do trabalho e meio ambiente do trabalho I. In: CONGRESSO DO CONSELHO NACIONAL DE PESQUISA E PÓS-GRADUAÇÃO EM DIREITO (Conpedi-Curitiba), 15. Anais... Florianópolis: Conpedi, 2016. 23p. Disponível em: <https:// www.conpedi.org.br/publicacoes/02q8agmu/ zwub6y85/36843g0tnaU5a9Az.pdf > . Acesso em: 20 nov. 2016.

PIERANTONI, Célia R. As reformas do Estado, da saúde e recursos humanos: limites e possibilidades. Ciência \& Saúde Coletiva, Rio de Janeiro, v. 6, n. 2, p. 341-360, 2001.

PIERANTONI, Célia R.; VARELLA, Thereza C.; FRANÇA, Tania. Recursos humanos e gestão do trabalho em saúde: da teoria à prática. In: CAMPOS, Francisco E.; MACHADO, Maria H.; PIERANTONI, Célia R. (orgs.). Cadernos RH Saúde, Brasília, DF, v. 3, n. 1, p. 27-38, mar. 2016.

RODRIGUES, Paulo H. A. As organizações sociais na saúde, peça-chave para a privatização da saúde. 2016. Disponível em: <http://cebes.org. br/2016/11/as-organizacoes-sociais-na-saudepeca-chave-para-a-privatizacao-da-saude/> . Acesso em: 23 nov. 2016.

SANDÍN ESTEBAN, María. P. Pesquisa qualitativa em educação: fundamentos e tradições. Tradução de Miguel Cabrera. Porto Alegre: AMGH, 2010.

SANTINI, Stela M. L. et al. Dos 'recursos humanos' à gestão do trabalho: uma análise da literatura sobre o trabalho no SUS. Trabalho, Educação e Saúde, Rio de Janeiro, v. 15, n. 2, p. 537-559, 2017. Disponível em: <http://www.scielo.br/ scielo.php?script $=$ sci_arttext $\&$ pid $=$ S1981-
$77462017005002109 \& \operatorname{lng}=$ pt\&nrm $=$ iso $>$. Acesso em: 29 mar. 2017.

SANTOS, Eliziane J.; LACAZ, Francisco A. C. Análise preliminar sobre plano de carreiras, cargos e salários e suas repercussões na gestão do trabalho em saúde em dois municípios da Grande São Paulo. In: CONGRESSO BRASILEIRO DE POLÍTICA, PLANEJAMENTO E GESTÃO EM SAÚDE, 2, Belo Horizonte, 2013. Disponível em: <http://www.politicaemsaude. com.br/anais/trabalhos/publicacoes/061.pdf $>$. Acesso em: 6 maio 2016.

SANTOS, Lenir. Administração pública e a gestão da saúde. In: SANTOS, Nelson R.; AMARANTE, Paulo D. C. (orgs). Gestão pública e relação público privado na saúde. Rio de Janeiro: Cebes, 2010. p. 68-86. (Cap. 4).

SCHIMITT, Alcione V. O Programa Nacional de Publicização. Jus Navigandi, Teresina, v. 11, n. 1.187, p. 1-2, out. 2006. Disponível em: $<$ http://jus.com.br/artigos/8994/o-programanacional-de-publicizacao-pnp $>$. Acesso em: 10 nov. 2016.

TONI, Wladimir P. Distinguindo a terceirização da 'pejotização'. 2015. Disponível em: < https:// wptoni.jusbrasil.com.br/artigos/217543990/ distinguindo-a-terceirizacao-da-pejotizacao >. Acesso em: 16 jan. 2017.

TRIBUNAL DE CONTAS DA UNIÃO (TCU). Informativo de licitações e contratos n. 146. Relatório de auditoria operacional. Ata n. 47/2013 da sessão ordinária de 27/11/2013. 84p. Disponível em: <htps://www.google. com. br/url? sa $=$ t \&rct $=j \& q=\&$ esr $x=s \&$ sou $\mathrm{rce}=$ web $\& \mathrm{~cd}=5 \& \mathrm{cad}=\mathrm{rja} \&$ uact $=8 \& \mathrm{ved}=0$ ahUKEwij_dXO0z3VAhUFg5AKHQ21CFM QFghDMAQ\&url=http:\%3A \%2F\%2Fpor tal.tcu.gov.br\%2Flumis \%2Fportal \%2File \%2fileDownload.jsp \%3FileId \%3D8A182 A24D309895014D33AD8FA2A63\%26inlin e\%3D1\&usg =AFQJCNEL192Rj8poreO6asY LnlEFV8opbQ>. Acesso em: 22 jul. 2017.

VIANA, Ana L. D.; DAL POZ, Mário R. A reforma do sistema de saúde no Brasil e o Programa de Saúde da Família. Physis: Revista 
de Saúde Coletiva, Rio de Janeiro, n. 15, supl., p. 225-264, 2005.

VIEIRA, Mônica. Recursos humanos em saúde. In: PEREIRA, Isabel B.; LIMA, Júlio C. F. Dicionário da Educação Profissional em Saúde. Rio de Janeiro: Escola Politécnica de Saúde Joaquim Venâncio; Editora Fiocruz, 2009. Disponível em: <http://www.sites.epsjv. fiocruz.br/dicionario/verbetes/rechumsau. html>. Acesso em: 20 out. 2015.
ZOLET, Rachel. O contrato de gestão entre o poder público e organizações sociais como instrumento de fuga do regime jurídico administrativo. Jus Navigandi, Teresina, v. 16, n. 2.792, 22 fev. 2011. Disponível em: <https:// jus.com.br/artigos/18550>. Acesso em: 20 jun. 2016.

Recebido em 31/05/2017.

Aprovado em 13/09/2017. 